\title{
On the Positive Electrification of Snow Crystals in the Process of Their Melting (II)
}

\author{
By Choji Magono and Katsuhiro Kikuchi \\ Department of Geophysics, Hokkaido University, Sapporo \\ (Manuscript received 24 August 1965)
}

\begin{abstract}
The electric charge on falling snow crystals was measured in the process of their melting. The results of measurements showed that the snow crystals obtained positive charge of an order of $10^{-4}$ esu on the average and the majority of snow crystals changed their sign of charge from negative to positive.

It was observed that numerous air bubbles were produced in melting snow crystals with a subsequent erruption from their melting surface. It was also confirmed that the more complex the crystal shape, the more positive charge the crystal acquired in the melting state.

From the results of the measurement, it was suggested that snow crystals obtained positive charge in the course of melting when air bubbles errupted from the melting snow crystals, carrying off negative charge.
\end{abstract}

\section{Introduction}

In the previous paper by the authors (1963), many observational phenomena which suggested that snow crystals were electrified positively in the process of melting during free fall were reported. For example, we have reports by Chalmers (1957), Reiter (1956), Fitzgerald and Byers (1958), and Orikasa (1961). But no direct measurement of positive electrification of falling snow crystals in the process of their melting have been made to date.

The previous study of the authors was carried out in order to confirm this. However the measurements were limited to the sign of charge on snow crystals, and the number of measurement made on individual snow crystals was insufficient to confirm the mechanism.

In the winter of 1961, an apparatus for measuring both the sign and the charge on individual falling snow crystals was designed, and numerous measurements using this apparatus were repeated on various kinds of snow crystal type on the summit of Mt. Teine. This paper will describe the results of observations in the second season.

\section{Measuring method of sign and charge on falling snow crystals}

The vertical cross-section of the measuring apparatus is shown in Fig. 1. The apparatus consisted of two metallic cylinders. A snow crystal falling in through an inlet in the roof of the observation hut, falls into the inner cylinder which is heated electrically from the outside, in an attempt to avoid effects of vapour from the heating wire. In almost all cases, the snow crystal completely melted to a droplet when it passed through the inner cylinder and went out through the bottom. The melted snow crystal, that is the drop, then falls into a narrow space where horizontal electric fields of 300 volt $/ \mathrm{cm}$ D.C. and 2000 volt $/ \mathrm{cm}$ A.C. are applied, as shown in the lower part of Fig. 1. When the drop melted from the snow crystal possessed any charge, it was assumed to leave a deflected and waved trajectory. The trajectory was observed by a close up camera.

The sign of charge on the drop melted from the falling snow crystal was determined by the direction of deflection of the trajectory, and the magnitude of the charge was measured by the amplitude of the waved 


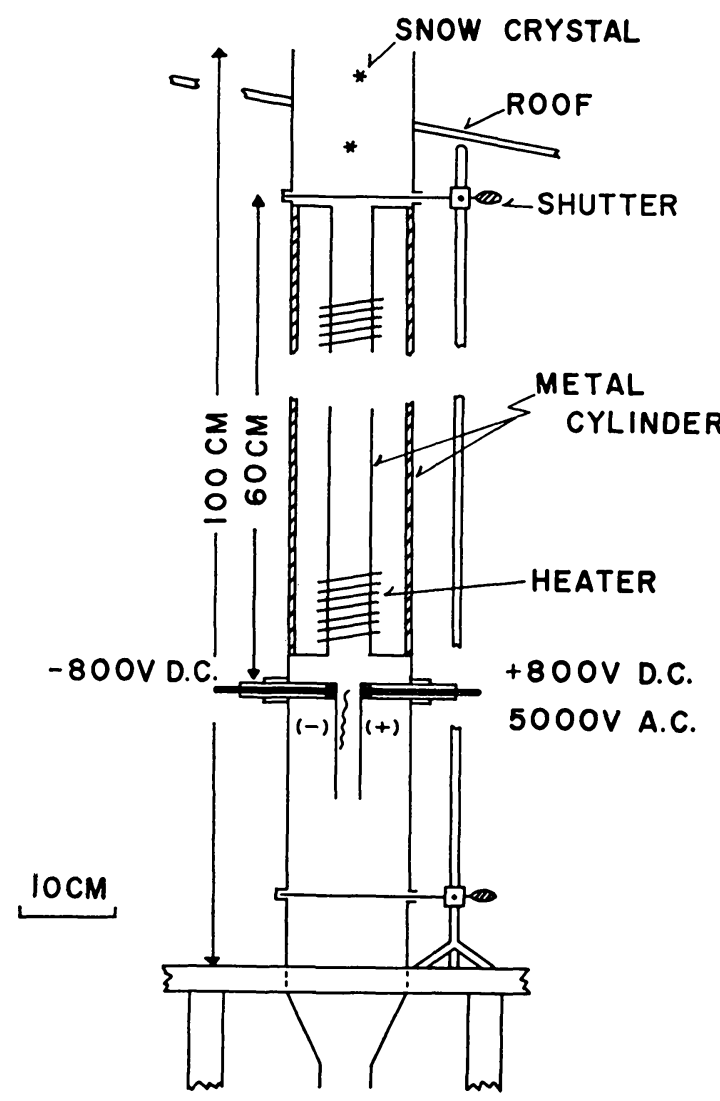

Fig. 1. Apparatus for measuring charge on a falling snow crystal in melting state.

trajectory according to Wells and Gerke method (1919), as follows:

$$
e / m=\sqrt{2} \pi^{2} A f^{2} \frac{300 d}{V} \sqrt{1}+\left(\frac{g}{2 \pi \lambda f^{2}}\right)^{2}
$$

where $e=$ charge of a drop

$m=$ mass of the drop

$A=$ amplitude of waved trajectory

$f=$ frequency of A.C.

$d=$ distance between two electrode plates

$V=$ potential difference between two electrode plates in volts

$g=$ gravitational acceleration

$\lambda=$ wave length of waved trajectory

All quantities except $V$ are shown in C.G.S. unit.

In the case of a melted drop, its mass may be measured by estimation of its falling speed. The falling speed was determined by wave length of the waved trajectory.
In order to ascertain that a snow crystal is electrified positively when it is melted, it was required to measure not only the charge on a melted drop but also the charge on a non-melted snow crystal. In the case of non-melted snow crystal, the method for determining the mass was difficult. Therefore the following method was used.

The falling speed and crystal type of a snow crystal were observed at first, then the size of the snow crystal was computed by Nakaya's observational result (1954). Again, using the crystal shape and the size, the mass of the snow crystals was calculated from Nakaya's empirical formula (1954).

Because it was impossible to measure the charge both before and after melting on the same falling snow crystal, the following method was used. At first, the charge on falling snow crystals was measured without melting for 30-60 minutes, then the charge on drops which were melted from other falling snow crystals was measured for 30-60 minutes. Such measurements were repeated during snowfall, and the results of melted drops and non-melted snow crystals were compared.

If the sign of charge on falling snow crystals did not change for several hours, the comparison method described above would be successful. But it was usual that the sign of charge on falling snow crystals changed according to the inverse relation between the charge of snow crystals and atmospheric electric field, as reported by Magono et al. (1957) and Orikasa (1961). Instead of the direct measurement of the sign of falling snow crystals before melting, therefore the sign of electric field was observed simultaneously with the measurement of the charge on melted drops, in order to determine the sign of falling snow crystals without melting.

\section{Observational results}

\subsection{Charge on falling snow crystals and melted drops}

Observational results of simultaneous measurement of charge and electric field are shown in Figs. 2, 3 and 4. In the figures, the horizontal axis shows time and the vertical axis shows charge and electric potential 


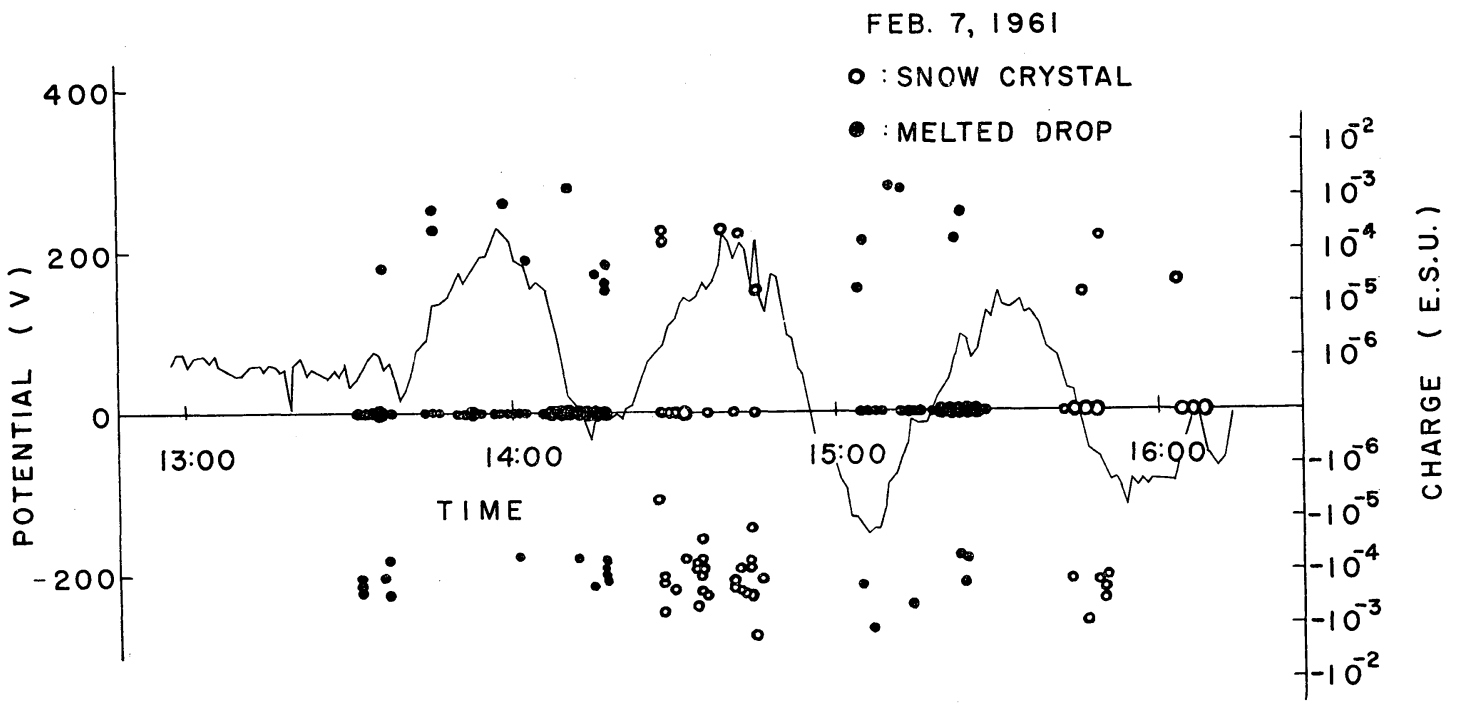

Fig. 2. Charge on falling snow crystals of needle type and on melted drops, and time change of potential at $2 \mathrm{~m}$ height above snow surface.

\section{SPATIAL DENDRITE}

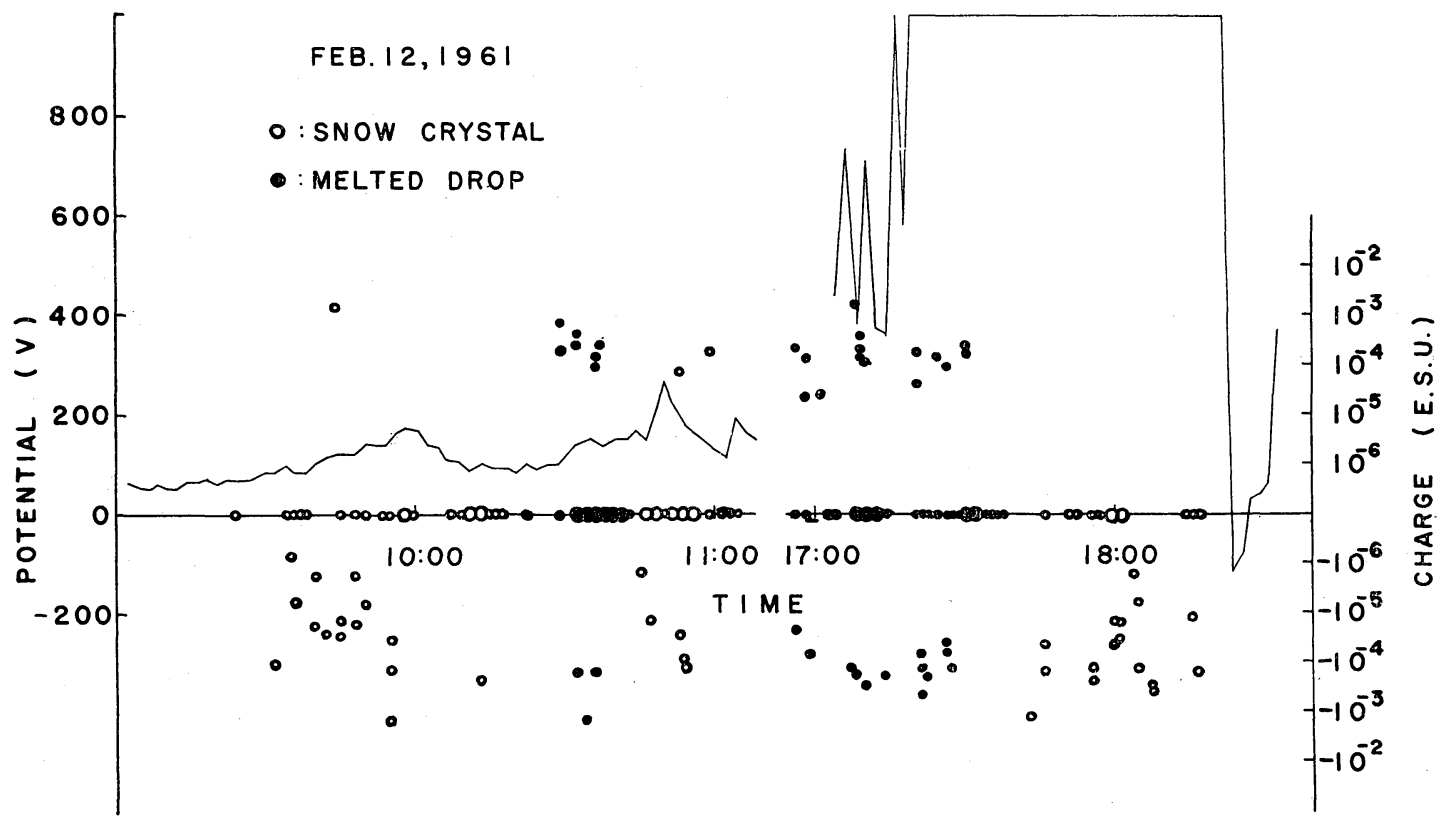

Fig. 3. Charge on falling snow crystals of spatial dendrite type and on melted drops, and time change of potential at $2 \mathrm{~m}$ height above snow surface.

at $2 \mathrm{~m}$ height above the surface of snow cover. Black dots and white dots indicate the charge on melted drops and on falling snow crystals respectively. The dots on the zero line show that the charge was so small that ts sign and magnitude were not measured.

Case of February 7, 1961. Snow crystals of needle type were predominant on this day. As seen in Fig. 2, a fairly steady positive potential was observed before the experiment 


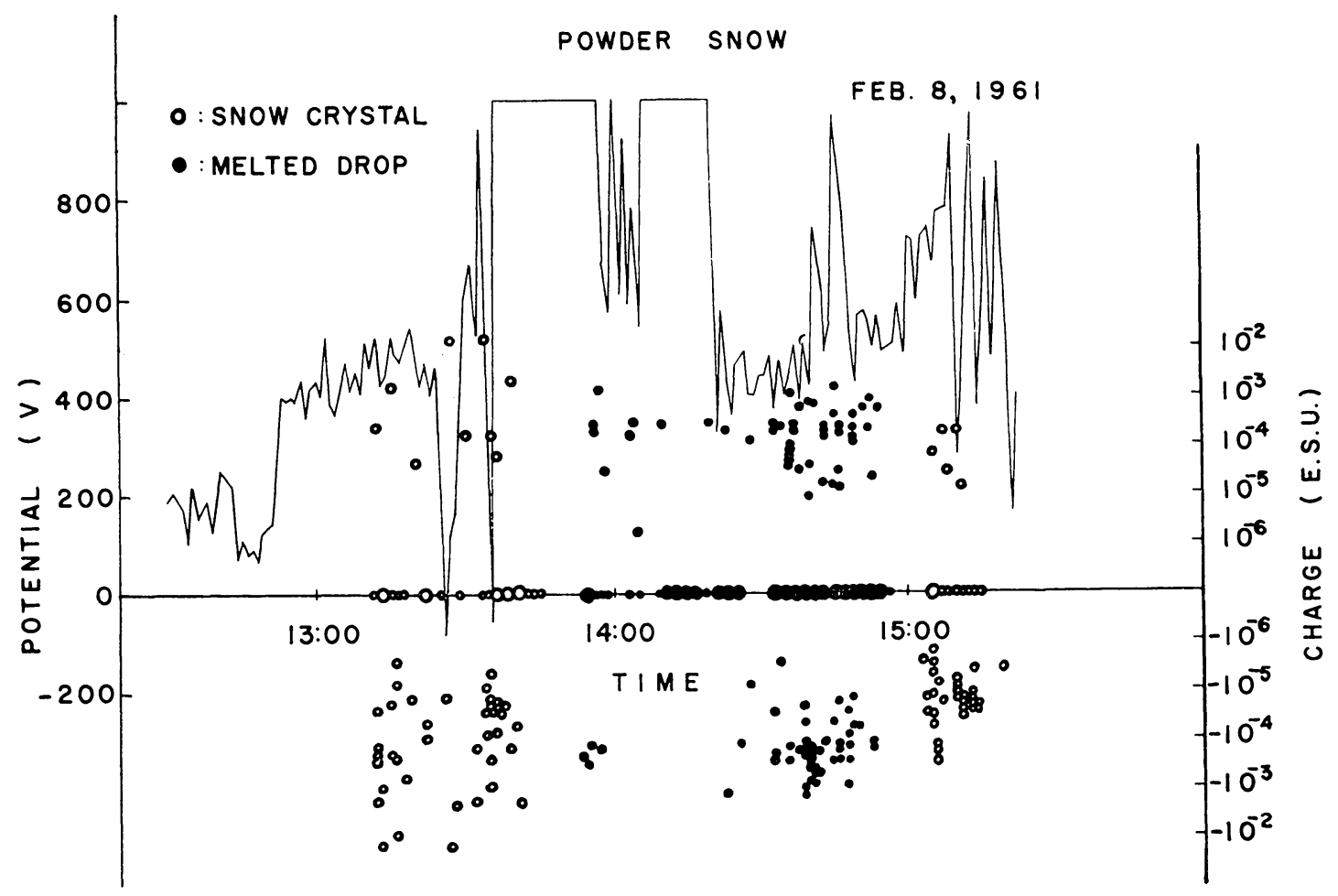

Fig. 4. Charge on falling snow crystals of powder type and on melted drops, and time change of potential at $2 \mathrm{~m}$ height above snow surface.

around 1300 hours. When the melting experiment of falling snow crystals commenced, the positive potential increased to about +200 volts. However after 1330 when the melting operation started, positive drops were observed more frequently than negative drops in spite of being under a positive electric field. This suggests that the positive drops were produced from negative crystals by melting, inasmuch as negative snow crystals may be assumed to be predominant under a positive electric field according to the inverse relation, as supposed from the pattern in the next period. After 1430 when the melting experiment was interrupted, negative snow crystals were predominant as may be surmized from the presence of a positive electric field.

The melting experiment was resumed again from 1500 , however no expected regular tendency in sign due to melting was observed, inasmuch as the electric field was not steady during the melting experiment.

Case of February 12. Spatial dendritic crystals were predominant in the morning of this day. As seen in Fig. 3, almost all the snow crystals were negative under a steady positive electric field till 1020 when the melting operation started. After 1020 the number of positive drops was greater than the negative even under a steady positive field. After the interruption of melting at 1050, negative snow crystals increased considerably.

The experiment was resumed in the evening under a strong positive field. During the melting period from 1650 to 1740 , the number of positive drops was greater than that of the negative. After the melting was terminated, snow crystals were found to be all negative.

Case of February 8. In the observation, snow crystals of powder type were predominant, and the electric field was always positive and strong as seen in Fig. 4. The number of positive drops was greater than negative drops during the melting operation, and negative snow crystals were predominant during the period of interruption of melting 
similar to the results on the February 12 .

As described above, the observational results obtained in the winter season clearly showed that falling negative snow crystals obtained positive charge when they were melted, although they did not always alter their sign.

\subsection{Comparison of charges of falling snow} crystals and melted drops

The measurement as described above was continued from 3rd to 15th February 1961. In order to check the effect of melting of snow crystals on their charge, the percentages of numbers of positive and negative snow crystals were compared with those of positive and negative melted drops with regard to each crystal type.

The results are shown in Figs. 5, 6 and 7 . In the figures, vertical and horizontal axes show the diameter of melted drops (equivalent diameter in the case of snow crystals) and charges on the snow crystals and the melted drops, respectively. White and black dots show the charges on non-melted snow crystals and on melted drops, respectively. Data corresponding to the sector-like area between the two broken lines were unobtainable, because their $\mathrm{e} / \mathrm{m}$ was smaller than the resolving power by this method. And trajectories of drops smaller than $15 \mu$ in diameter could not be taken by the close up camera.

The diameter of melted drops ranged from 30 to $400 \mu$ (roughly $150 \mu$ on the average),

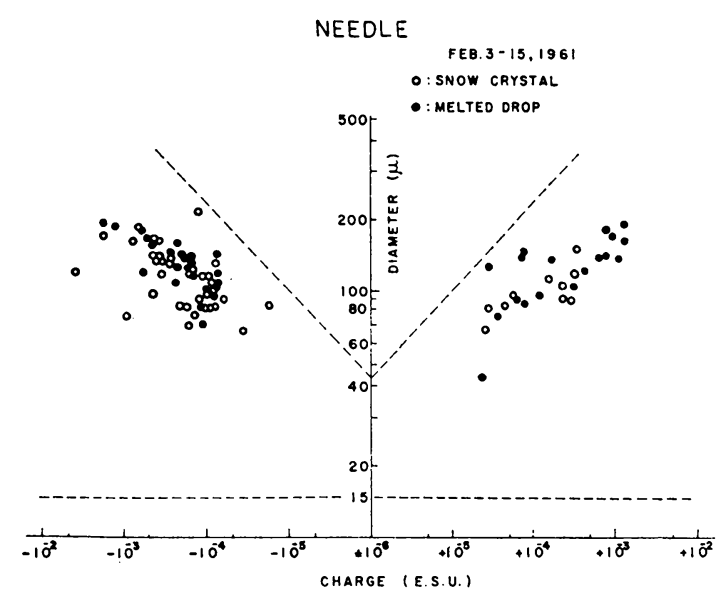

Fig. 5. Size $v s$ charge on snow crystals of needle type and on melted drops.

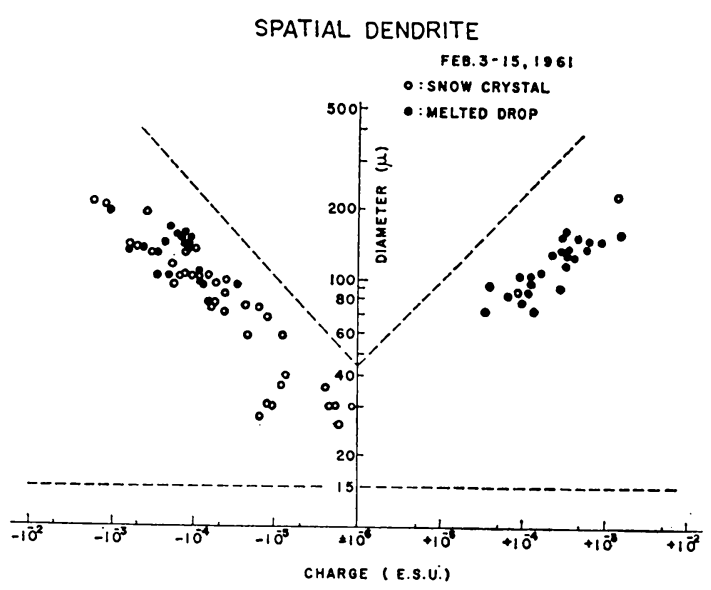

Fig. 6. Size vs charge on snow crystals of spatial dendrite type and on melted drops.

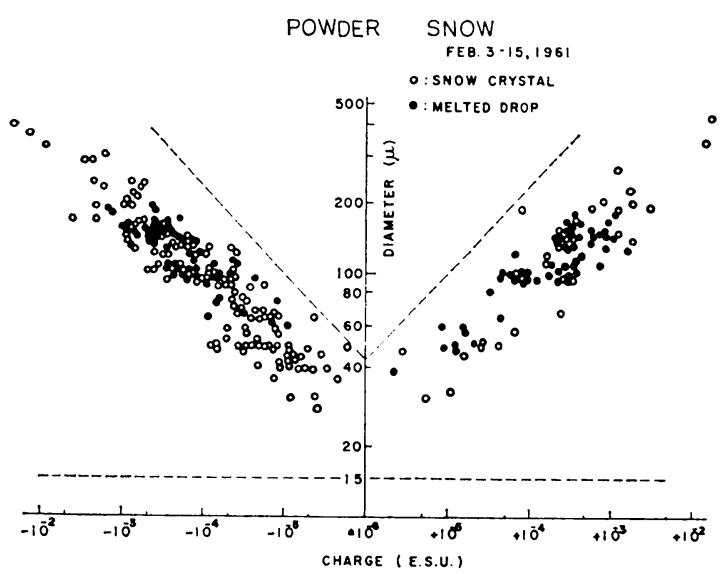

Fig. 7. Size $v s$ charge on snow crystals of powder type and on melted drops.

and the magnitude of charge on individual snow crystals or melted drops ranged from $10^{-6}$ to $10^{-2}$ esu. In the figures, it is also seen that the greater the size, the greater the charge.

As seen in the right half of Fig. 5, the number of positive melted drops was greater than that of positive snow crystals, while as seen in the left half of the figure, the number of negative drops was smaller than that of negative snow crystals. Likewise in Fig. 6 of spatial dendritic crystals, it may be seen that the majority of negative charges were held by snow crystals, but almost all positive charges were held by melted drops. This tendency was the same in the case of powder snow as seen in Fig. 7. These results 
strongly suggest that a considerable part of negative snow crystals changed to positive when they were melted.

For the convenience of comparison, the rate of change of sign of charge due to melting is shown in the form of percentage of numbers of snow crystals and melted drops in Fig. 8. The rate of change is also shown for each snow crystal type, namely, needle, powder snow and spatial dendrite. Numbers of measurement are shown at the column at the right end of the figure.

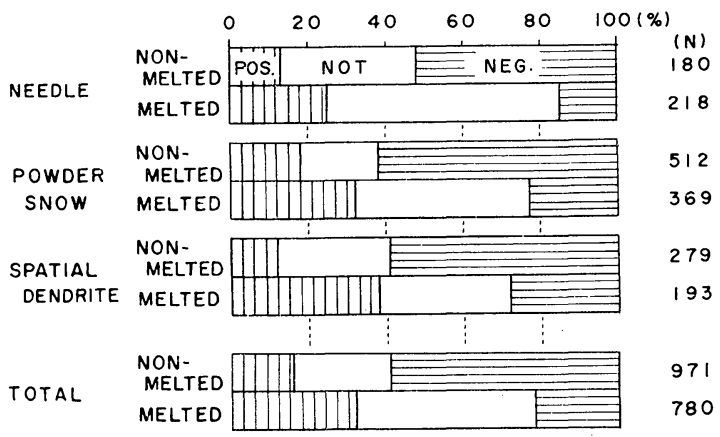

Fig. 8. Change in the percentage of positive, not detected and negative falling snow crystals of various types due to melting.

In the case of needle type, the percentages of positive (vertically hatched part), not detected (white part) and negative snow crystals (horizontally hatched part) were 12 , 36 and $52 \%$ respectively, while for the melted drops, the percentages of positive, not detected and negative drops were 26, 60 and 14\% respectively. It is noted that the percentage of positive increased twofold and that of negative decreased to one third of the original percentage. In the case of powder snow and spatial dendrite likewise, the percentage of positive considerably increased, while the percentage of negative decreased due to melting. The percentage for the total number for the three types is shown at the bottom of Fig. 8. It is seen here that the percentage of positive increased to twice of that of the original value, while the percentage of negative decreased to about one third due to melting.

The mean electric charge on snow crystals of the three types, melted and non melted is shown in Table 1.

It is noted in the table above that mean
Table 1. Mean electric charge on snow crystals, melted and non melted

\begin{tabular}{|c|c|c|c|c|c|}
\hline \multicolumn{3}{|c|}{ Non melted } & \multicolumn{3}{|c|}{ Melted } \\
\hline $\begin{array}{c}\text { Sign } \\
\text { of } \\
\text { charge }\end{array}$ & $\begin{array}{l}\text { Mean } \\
\text { charge }\end{array}$ & $\begin{array}{c}\text { Number } \\
\text { of } \\
\text { observa- } \\
\text { tion }\end{array}$ & $\begin{array}{c}\text { Sign } \\
\text { of } \\
\text { charge }\end{array}$ & $\begin{array}{l}\text { Mean } \\
\text { charge }\end{array}$ & $\begin{array}{l}\text { Number } \\
\text { of } \\
\text { observa- } \\
\text { tion }\end{array}$ \\
\hline+ & $\begin{array}{c}4.2 \times 10^{-4} \\
\mathrm{esu}\end{array}$ & 142 & + & $\begin{array}{c}3.5 \times 10^{-4} \\
\mathrm{esu}\end{array}$ & 240 \\
\hline $0^{*}$ & & 257 & $0^{*}$ & & 377 \\
\hline - & $3.6 \times 10^{-4}$ & 572 & - & $3.0 \times 10^{-4}$ & 163 \\
\hline $\begin{array}{r}\text { Tot } \\
* \text { Cha }\end{array}$ & arcas & 971 & & & 780 \\
\hline
\end{tabular}

charges of positive, negative and melted, non melted are roughly the same, however the ratio of number of the positive particles to the negative particles increased considerably by melting. This change in the charge and the ratio corresponds to that each snow crystal obtained $+2 \times 10^{-4}$ esu on the average when it was melted.

From the results described hitherto, we may state that we have confirmed statistically that falling snow crystals obtained considerable amount of positive charge when they were melted. And it is considered that the magnitude of the positive charge thus obtained was of the same order as that of the original negative charge which the snow crystals carried before melting, because the percentage of non-detected charge did not decrease but rather to some extent increased by melting.

\section{Measurement by suspended snow crystals}

As described hitherto, positive falling snow crystals were observed before melting although in a small percentage, therefore the melting effect on the positive electrification could only be detected statistically by such a method. In order to determine the positive electrification of snow crystals by melting more exactly, it becomes necessary to measure the sign of charge on the same snow crystal both before and after melting. For this purpose, the following experiment was carried out.

\subsection{Measuring method of charge on the same snow crystal before and after melting}

A natural snow crystal was suspended at 
the end of a silk filament in a narrow space of horizontal electric field with 225 volt $/ \mathrm{cm}$ as shown in Fig. 9. The silk filament was insulated from other systems. An infra-red lamp was used to melt the snow crystal from above.

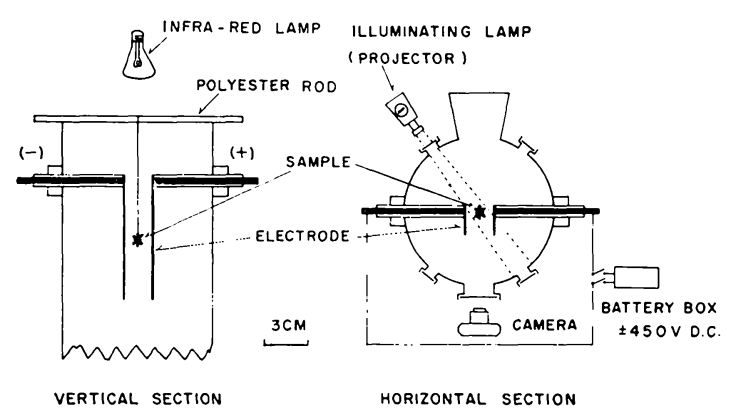

Fig. 9. Apparatus for measuring the charge on a suspended snow crystal in melting state.

The measuring procedure was as follows.

1. A snow crystal was suspended in the space.

2. The horizontal electric field was applied only for a very short period (about $0.2 \mathrm{sec}$ ) and the direction of movement of the snow crystal was observed by a close up camera. If the electric field was applied for a longer period, further experiment by this snow crystal would become impossible, because the snow crystal in almost all cases, became attached to one of the electrode plates.

3. The snow crystal was melted by the infra-red lamp without an electric field.

4. The electric field was applied for a short period and the direction of movement of the melted drop was observed.

Because the purpose of this experiment was only to determine the sign of charge, in other words to observe the direction of movement from the neutral point, the position of the moving snow crystal was recorded during its movement by camera. Therefore, the magnitude of the deviation from the neutral point itself was not important.

Some examples are shown in the pictures of Fig. 10. The signs of electrode plates are given at the top of each picture. The upper three pictures, Figs. 10-a, 10-b and 10-c show successive movements of a hexagonal graupel due to positive electrification in melting state. In the case of the graupel, it had no charge before melting as seen in Figs. $10-a$ and 10-b, but after melting it was pulled strongly toward the negative eletrcode plate, showing it was charged positively as seen in Fig. 10-c.

In the case of a powder snow, it was charged negatively before melting as seen in Fig. 10-d. During melting it had already obtained a positive charge when the electric field was applied to observe its sign. After melting it was charged positively. Fig. 10-g shows the behavior of a rimed dendritic crystal under no electric field. When the electric field was applied in the process of melting, it was pulled toward the positive electrode, as seen in Fig. 10-h. But as melting proceeded, it was pulled toward the negative electrode as seen in Fig. 10-i. This means that the rimed crystal was negative at first before melting, then it obtained a positive charge larger than the original negative charge by melting.

\subsection{Change in the sign of charge on snow crystals due to melting}

It was difficult in this experiment to measure the magnitude of charge on each suspended snow crystal, however it was easy to determine the sign of charge both before

Table 2. Change in sign of charge on snow crystals due to melting

\begin{tabular}{|c|c|c|c|}
\hline \multicolumn{2}{|c|}{ Before melting } & \multicolumn{2}{|c|}{ After melting } \\
\hline $\begin{array}{l}\text { Sign of } \\
\text { charge }\end{array}$ & $\begin{array}{l}\text { Number of } \\
\text { observation }\end{array}$ & $\begin{array}{l}\text { Sign of } \\
\text { charge }\end{array}$ & $\begin{array}{l}\text { Number of } \\
\text { observation }\end{array}$ \\
\hline \multirow{3}{*}{+} & \multirow{3}{*}{41} & + & 40 \\
\hline & & 0 & 0 \\
\hline & & - & 1 \\
\hline \multirow{3}{*}{0} & \multirow{3}{*}{49} & + & 26 \\
\hline & & 0 & 19 \\
\hline & & - & 4 \\
\hline \multirow{3}{*}{-} & \multirow{3}{*}{94} & + & 53 \\
\hline & & 0 & 6 \\
\hline & & - & 35 \\
\hline & & Total & 184 \\
\hline
\end{tabular}




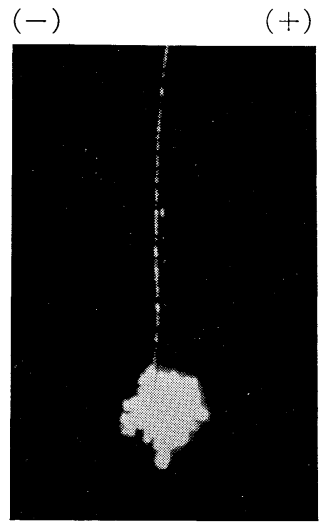

a. Before melting

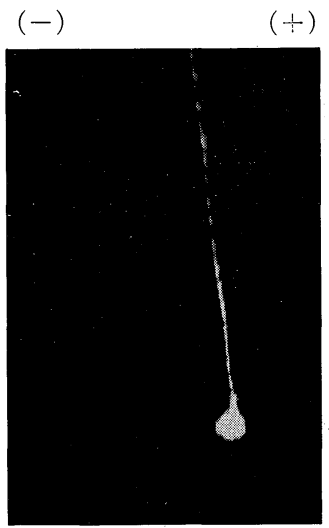

d. Before melting

no electric field

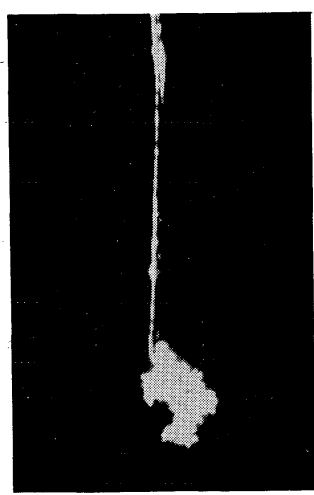

g. Before melting

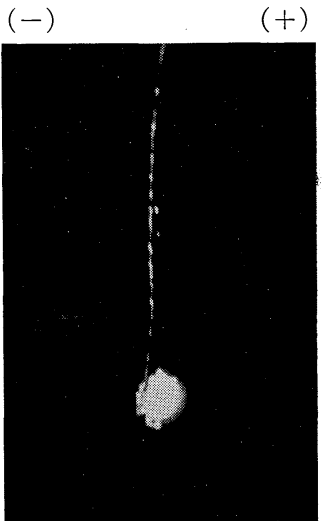

b. During melting

Hexagonal graupel

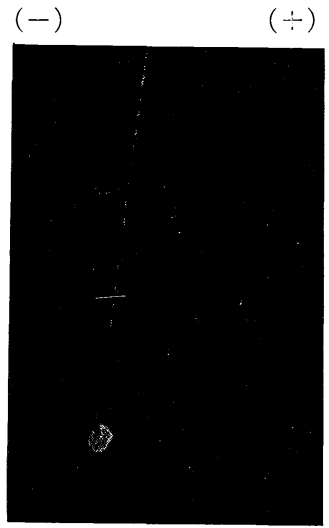

e. During melting

Powder snow

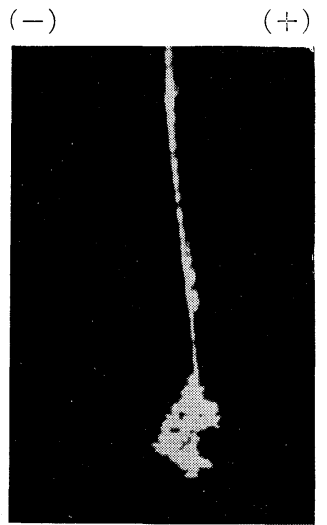

h. During melting

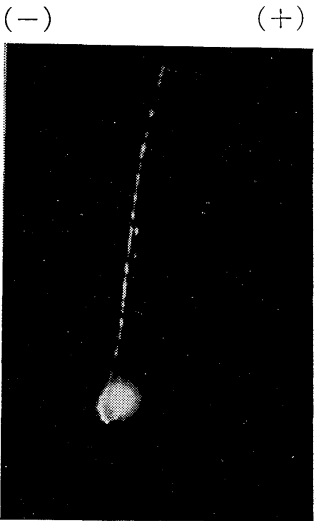

c. After melting 
and after melting the same snow crystal. Such experiments were made on 184 snow crystals of various types, including ice fragments. The result is shown in Table 2 .

In the table above, $O$ means that the sign was not detected because the charge was too small to measure the direction of deviation.

As seen at the upper column of Table 2, positive snow crystals were all positive also after melting except for one crystal. This was of course because the positive charge by melting was added to the original positive charge. The exceptional single case may have resulted from observational error. In case of non charged crystals before melting, about a half of them were charged positively after melting. About $40 \%$ of them were still non charged after melting. About $10 \%$ of non charged snow crystals were charged negatively after melting. This was not explained by the positive electrification theory. Usually non charged snow crystals were very small in size. Therefore it was difficult to determine the sign of such small snow crystals. The exceptional results of about $10 \%$ in the case of non charged snow crystals may have resulted from observational error due to their small size.

In the case of negative snow crystals before melting, more than a half of them changed to positive drops after melting. 5\%

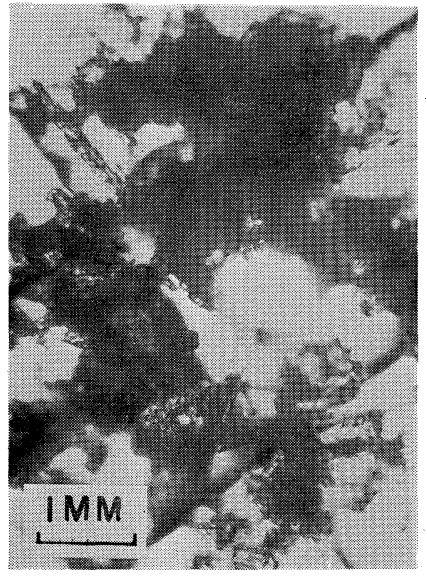

a. Before melting

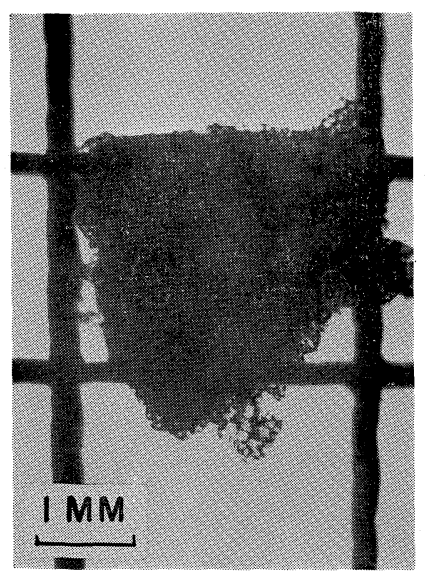

d. Before melting

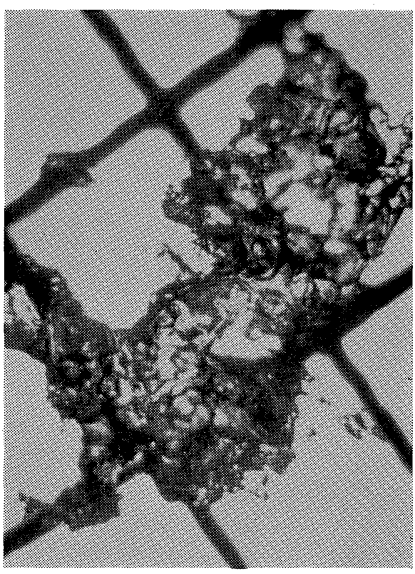

b. During melting

Snowflake in melting state

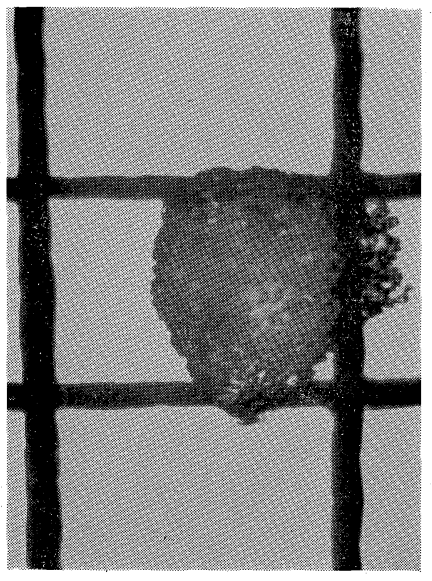

e. During melting

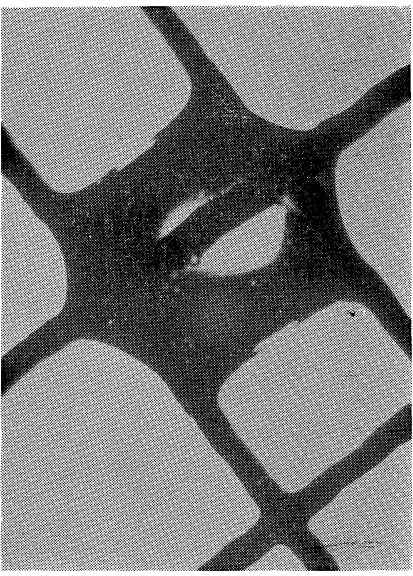

c. After melting

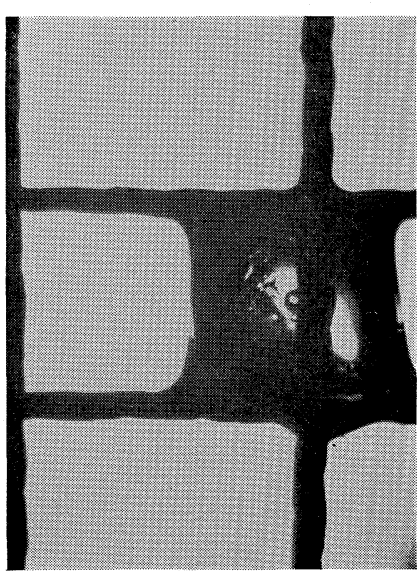

f. After melting

Graupel in melting state

Fig. 11. Air bubbles produced in a melting snowflake and graupel. 
of them changed to not detected, losing its negative charge. This means that the magnitude of positive charge obtained by melting was nearly the same as the original negative charge. $33 \%$ of negative snow crystals were still negative after melting. This means that the magnitude of the original negative charge was greater than the positive charge obtained by melting.

The result described in Table 2 may be summarized as follows. Except for 5 of 184 snow crystals, all snow crystals obtained positive charge, the magnitude of which was comparable with or about twice of the original negative charge during the melting process.

\subsection{Air bubbles produced in melting snow crystals}

Dinger and Gunn (1946) suggested that ice pieces were charged positively during the melting process by the erruption of negative air bubbles from the melting surface of an ice piece. Therefore it may be important to observe whether air bubbles actually errupt from the surface of natural melting snow crystals. Observations were made in order to confirm this, as shown in the successive pictures of Fig. 11.

A snowflake was placed on a mesh to melt and was observed under a microscope as seen in Fig. 11-a. As its melting proceeded, numerous air bubbles were produced as seen in Fig. 11-b, and these errupted from the melting surface, although the erruption itself is not clear in the picture. Even after complete melting, some air bubbles were left in the drop as seen in Fig. 11-c. These air bubbles would errupt from the surface of the drop sooner or later, because normally raindrops have no air bubbles in them. The lower three pictures of Fig. 11 also show a similar process of air bubble production in a graupel in the melting process.

It was difficult to count exact number of air bubbles, however by rough estimation, about 50 air bubbles on average were produced in the melting process of a snowflake or graupel.

4.4 Positive electrification by melting, and crystal type

If air bubbles in the melting process play a main role to generate the positive charge on a melting snow crystal, it may be surmized that the more complex the crystal shape is, the stronger the positive charge produced will be, because, for example, a snow crystal of such single shape as single plate will not produce many air bubbles in its melting state.

In order to check this relation, the grade of complexity of various types of snow crystals including icicle and ice fragments was noted, and the results were rearranged for the grade of shape complexity as shown in Fig. 12. The shapes of snow crystals are given at the left end of the figure. It is considered that air bubbles in the melting process increase in the following order: plate and plane dendrite, powder snow, spatial dendrite, snowflake, and graupel.

In Fig. 12, it may be seen that the ratio of positive increased after melting for each crystal type, and that the grade of the increase of the complex types such as spatial dendrite and snowflake was greater than that of simple crystal shapes such as plate or plane dendrite. Particularly in the case of spatial dendrite, all snow crystals changed to positive after melting. In total, the ratio of positive increased threefold, while the ratio

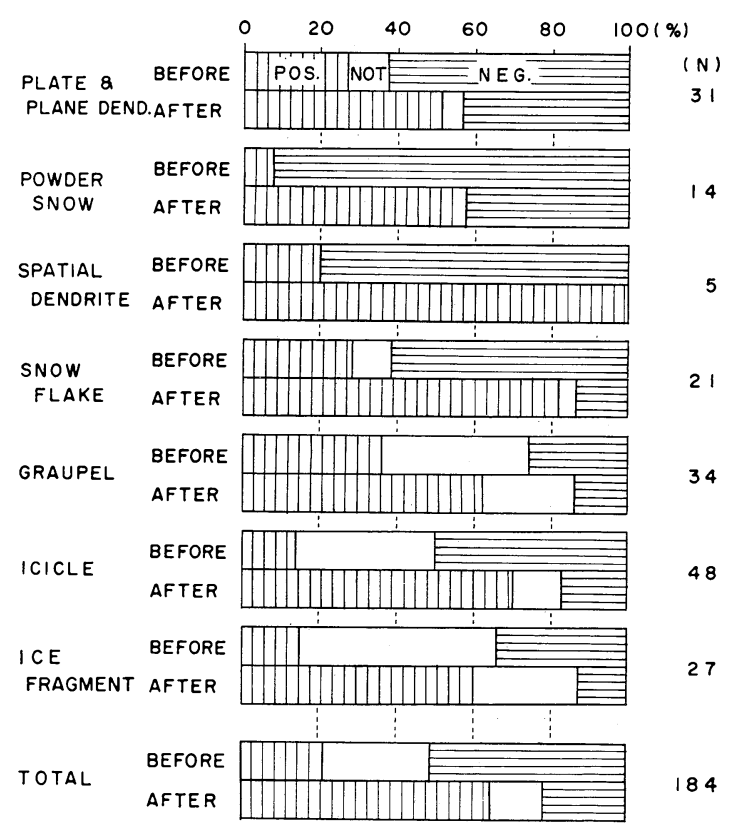

Fig. 12. Change in the percentage of positive, not detected and negative suspended snow crystals of various types due to melting. 
of negative decreased to a half of the original ratio.

By the results described above, it was also confirmed that air bubbles have a fairly large effect on the positive electrification of melting snow crystals.

\section{Consideration}

It was confirmed that snow crystals obtained positive charge during melting and the magnitude of the positive charge was greater than the original negative charge before melting, or at least was of the same order as the negative charge. And it was confirmed that this positive electrification was closely related to the air bubbles which were produced in the melting state of falling snow crystals.

The average positive charge which was acquired by melted snow crystals was roughly $2 \times 10^{-4}$ esu for the average size of $150 \%$. This value is comparable with that of positive raindrops which were observed in steady rainfall by many researchers hitherto. However it is noted that this average size of $150 \mu$ is fairly smaller than that of the usual raindrop size in steady rainfall. Because it is usual that the larger the drop, the larger the charge, this magnitude of positive charge on melted droplets of this experiment seems to be relatively greater than that of usual raindrops. Concerning this, the following explanation may be given.

In natural snowfall, melting of snow crystals commences gradually around $0^{\circ} \mathrm{C}$ level, while in the experiment falling snow crystals were melted rapidly. This high rate of melting perhaps may have been related to the large magnitude of the positive charge, because, after Dinger and Gunn's experiment, the more rapid the melting, the greater was the positive electrification of ice pieces.

About the negative surface electric field under a steady rainfall, following qualitative explanation was made. Since snow crystals obtain positive charge when they are melted, it is sure that negative charge of the same magnitude as the positive charge is carried off by ions or droplets due to air bubble erruption from the melting snow crystals. Therefore it is considered that negative space charge is produced near the melting level after the melting snow crystals fall as positive raindrops and the production of such negative space charge continues and is accumulated as long as the steady snowfall, that is, the steady rainfall, continues.

On the other hand, positive space charge due to positive falling raindrops will be produced near the ground surface and will establish a positive surface electric field as reported by the authors (1961), however the effect of the positive space charge on the surface electric field will be overcomed in a short time by that of the negative space charge above, because the positive space charge is not accumulated even if the steady rainfall continues. Accordingly a negative surface electric field will be established in the steady rainfall.

\section{Acknowledgments}

The authors express their best thanks to the Hokkaido Broadcasting Company whose sending station at the summit of Mt. Teine offered many facilities for this work.

The expense of this work was defrayed by the Special Fund for Scientic Research of the Educational Ministry of Japan.

\section{References}

Chalmers, J.A., 1957: Atmospheric Electricity. Pergamon Press, p.p. 192 and 194.

Dinger, J.E. and R. Gunn, 1946: Electrical effects associated with a change of state of water. Terr. Mag. atmos. Elec., 51, 477-494.

Fitzgerald, D.R. and H.R. Byers, 1958: Aircraft observations of convective cloud electrification. Recent Advances in Atmosfineric Electricity. Pergamon Press, p.p. 245-268.

Magono, C., K. Orikasa and H. Okabe, 1957: The charge on precipitation elements and surface electric potential gradient. J. Fac. Sci., Hokkaido Univ., Ser. VII, 1, 7-20.

, and , 1961: On the surface electric field caused by the space charge of charged raindrops. J. meteor. Soc. Japan, Ser. II, 39, 1-11.

-- - , and K. Kikuchi, 1963: On the positive electrification of snow crystals in the process of their melting. J. meteor. Soc. Japan, Ser. II, 41, 270-277.

Nakaya, U., 1954: Snow Crystals. Harvard Univ. Press, 111.

Orikasa, K., 1961: On the disturbance of the surface electric field caused by snow fall. $J$. 
Japanese Soc. Snow and Ice, 23, 81-90. (in Japanese)

Reiter, R., 1956: Results of two year's synoptic atmospheric electric recordings at seven mountain stations between 700 and 3000 meters above sea level. Technical Report, Contract
No. AF (514)-732-C, Amer. Army.

Wells, P.V. and R.H. Gerke, 1919: An oscillation method for measuring the size of ultramicroscopic particles. J. Amer. chem. Soc., 41, 312329.

\title{
降雪の融解による正荷電について（II）
}

\author{
孫野長治 - 菊地勝弘 \\ 北海.道大学理学部地球物理学教室
}

手稲山に打いて, 降雪を融解させてその電荷を測定し, それを融解させない降雪の電荷と比較した。その結果, 落 下中の雪の結晶は, 融解とより $10^{-4}$ e.s.u. の order の正電荷を獲得した。また, 最初多く負の電荷を持っていた 雪の結晶は, 融解とより正電荷を得ることが確かめられた。その際, 結晶の外形が複雑なほど正電荷を得る割合が高 かった。さらに, 融解中の雪の結晶の表面から直径数十 $\mu$ 程度の気泡が次々飞現われ, 破裂するのが観測された。 これ等の観測結果から, 雪の結晶は融解飞より正電荷を得るのは, 融解中の結晶から生成された気泡が破裂して負の 電荷を持ち去るためと考えられる。 